\title{
Importância da Qualidade do Sono em Universitários e Médicos Residentes
}

\author{
Maria Ligia Juliano \\ Cirurgiã dentista, Ortodondista, Doutora, Professora Afiliada, Neuro-Sono, UNIFESP, São Paulo-SP, Brasil.
}

Vários processos fisiológicos e neuro-cognitivos ocorrem durante o sono, como por exemplo a consolidação da memória e processos metabólicos. Entre os efeitos da privação do sono estão a dificuldade de concentração, a degradação da atenção e um impacto negativo na capacidade psicomotora, também associados a um aumento na taxa de erro e redução na capacidade de realização de tarefas ${ }^{1}$. Além disso, a privação do sono tem influência nas funções endócrinas, como intolerância à glicose e alteração do cortisol. Os mecanismos do processo de recuperação dos danos causados pela privaçáo do sono são mais complexos do que se pensava anteriormente, pois são necessárias muitas horas de sono para retomar a normalidade do ciclo sono-vigília ${ }^{2}$.

Carvalho TMCS et al. ${ }^{3}$, em estudo publicado neste volume, avaliaram e compararam a qualidade do sono e a sonolência diurna de estudantes universitários de duas áreas do conhecimento, Exatas e Saúde. Embora o estudo tenha tido a grande limitação de avaliar a qualidade do sono apenas por questionário e escala de sonolência, e não por polissonografia, os resultados mostraram que houve má qualidade de sono e sonolência diurna em ambos os grupos de estudantes, não havendo diferença significante entre os grupos. O grupo de estudantes da área de Saúde apresentou maior porcentagem de alunos com má qualidade de sono e maior sonolência excessiva diurna. Este estudo traz uma contribuição relevante porque comprova a privação de sono tão comum na atualidade, principalmente na população jovem. Inferindo que esses alunos em pouco tempo poderão ser médicos residentes com a responsabilidade de cuidarem de pacientes, devendo tomar decisóes importantes tanto no diagnóstico como nas condutas para tratamento, podemos dizer que a privação de sono típica de médicos residentes poderá interferir drasticamente nas tomadas de decisão terapêutica. A pri- vação de sono pode afetar a saúde, as emoçóes e a qualidade no atendimento de pacientes ${ }^{4}$. Estudos mostram um pior desempenho de médicos residentes após privação do sono aguda ou crônica. Uma pesquisa feita com 697 residentes de medicina mostrou uma incidência de acidentes automobilísticos 6,7 vezes maior nesta população, nos quais o residente dormiu dirigindo o veículo5.

Durante muitos anos, houve a preocupação de que médicos residentes pudessem cometer erros decorrentes do fato de ter sono insuficiente, no atendimento a pacientes. Em 2002, o Accreditation Council on Graduate Medical Education, organização responsável por garantir as boas condições de aprendizado dos médicos residentes nos Estados Unidos, estabeleceu regras para limitar o número de horas semanais que os residentes deveriam cumprir. As regras começaram a ser cumpridas a partir de Julho de $2003^{6}$, com o objetivo de melhorar a quantidade e qualidade do sono. A partir daí, muitos estudos foram feitos para entender os efeitos da redução do número de horas de trabalho sobre os médicos residentes, assim como avaliar mudanças nos desfechos dos pacientes internados. Esses trabalhos constataram uma diminuição no número de mortes de pacientes com diagnósticos graves, como infecções e insuficiência cardíaca ${ }^{7}$. Estas normatizaçôes deveriam ser pensadas e aplicadas na realidade brasileira, para melhorar tanto a qualidade de vida do médico residente como o atendimento aos pacientes.

$\mathrm{O}$ momento atual também exige que a sociedade esteja sempre alerta. $\mathrm{O}$ uso contínuo de redes sociais e de diversas formas de tecnologia, em horários cada vez mais abrangentes, tem aumentado significativamente a privação de sono. É preciso que a comunidade científica mostre cada vez mais, através de estudos de evidência, a importância da quantidade e qualidade do sono para manter a boa saúde e a longevidade. 


\section{REFERÊNCIAS}

1.Banks S, Dinges DF. Behavioral and physiological consequences of sleep restriction. J Clin Sleep Med 2007;3:519-28.

2.Banks S, Van Dongen HPA, Maislin G, Dinges DF. Neurobehavioral Dynamics Following Chronic Sleep Restriction: Dose-Response Effects of One Night for Recovery. Sleep 2010;33:1013-26.

3.Carvalho TMCS, Silva Junior II, Siqueira PPS, Almeida JO, Soares AF, Lima AMJ. Qualidade do Sono e Sonolência Diurna Entre Estudantes Universitários de Diferentes Áreas. Rev Neurocienc 2013;21(3):383-87.

http://dx.doi.org/10.4181/RNC.2013.21.854.5p

4.Kim HJ, Kim JH, Park KD, Choi KG, Lee HW. A survey of sleep deprivation patterns and their effects on cognitive functions of residents and interns in
Korea. Sleep Med 2011;12:390-6.

http://dx.doi.org/10.1016/j.sleep.2010.09.010

5.Kowalenko T, Kovalenko J, Grybowski M, Rabinovich A. Emergency medicine resident related auto accidents - is sleep deprivation a risk factor? Acad Emerg Med 2000;7:451.

6.Accreditation Council on Graduate Medical Education. Statement of Justification/ Impact for Final Approval of Common Standards Related to Resident Duty Hours. Accessed at http://www.acgme.org/acgmeweb/Portals/0/ PDFs_Definitions.pdf on 26 September 2013.

7.Shetty KD, Bhattacharya J. Changes in Hospital Mortality Associated with Residency Work-Hour Regulations. Ann Intern Med 2007;147:73-80.

http://dx.doi.org/10.7326/0003-4819-147-2-200707170-00161 